\title{
CORRECTION
}

\section{Correction to: Dramatic Innovations in the Treatment of Spinal Muscular Atrophy, But Many Unknowns Remain}

\author{
Chris Skedgel ${ }^{1}$ (1)
}

Published online: 25 February 2022

(C) The Author(s), under exclusive licence to Springer Nature Switzerland AG 2022

\section{Correction to: PharmacoEconomics}

https://doi.org/10.1007/s40273-021-01119-1

In this article ref 11 was incorrect incorrectly published as

Paracha N, Hudson P, Mitchell S, Sutherland CS. Systematic literature review to identify utility values in patients with spinal muscular atrophy (SMA) and their caregivers. Pharmacoeconomics. 2021. https://doi.org/10.1007/s40273021-01115-5 (Epub 18 Oct 2021).

It should have been

Sutherland, C.S., Hudson, P., Mitchell, S. et al. Systematic Literature Review to Identify Utility Values in Patients with Spinal Muscular Atrophy (SMA) and Their Caregivers. PharmacoEconomics (2021). https://doi.org/10.1007/ s40273-021-01115-5 (Epub 15 Dec 2021)

In the 2 nd sentence of the 7 th paragraph the supporting reference was incorrect. The correct reference number is reference 12 .
The original article can be found online at https://doi.org/10.1007/ s40273-021-01119-1.

\section{Chris Skedgel}

cskedgel@ohe.org

1 Office of Health Economics, London, UK 